\title{
AIP
}

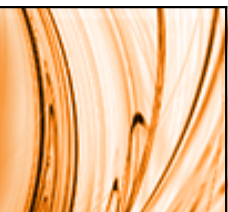

\section{Porosity-induced relaxation of strains in GaN layers studied by means of micro- indentation and optical spectroscopy}

Adel Najar, Michel Gerland, and Mustapha Jouiad

Citation: Journal of Applied Physics 111, 093513 (2012); doi: 10.1063/1.4710994

View online: http://dx.doi.org/10.1063/1.4710994

View Table of Contents: http://scitation.aip.org/content/aip/journal/jap/111/9?ver=pdfcov

Published by the AIP Publishing

\section{Articles you may be interested in}

Utilisation of $\mathrm{GaN}$ and InGaN/GaN with nanoporous structures for water splitting

Appl. Phys. Lett. 105, 223902 (2014); 10.1063/1.4903246

Surface phonon polariton characteristic of honeycomb nanoporous $\mathrm{GaN}$ thin films

Appl. Phys. Lett. 102, 101601 (2013); 10.1063/1.4794906

Improvement of microstructural and optical properties of GaN layer on sapphire by nanoscale lateral epitaxial overgrowth

Appl. Phys. Lett. 88, 211908 (2006); 10.1063/1.2207487

Optical activation of Eu ions in nanoporous GaN films

J. Appl. Phys. 99, 104305 (2006); 10.1063/1.2191647

Fabrication and properties of nanoporous GaN films

Appl. Phys. Lett. 85, 816 (2004); 10.1063/1.1774273

MIT LINCOLN

LABORATORY CAREERS

Discover the satisfaction of innovation and service

to the nation
- Space Control

- Air \& Missile Defense

- Communications Systems \& Cyber Security

- Intelligence, Surveillance and

Reconnaissance Systems

- Advanced
Electronics
- Tactical Systems
- Homeland
Protection
- Air Traffic Control

LINCOLN LABORATORY

MassachusetTs Institute of TeChNOLOgY

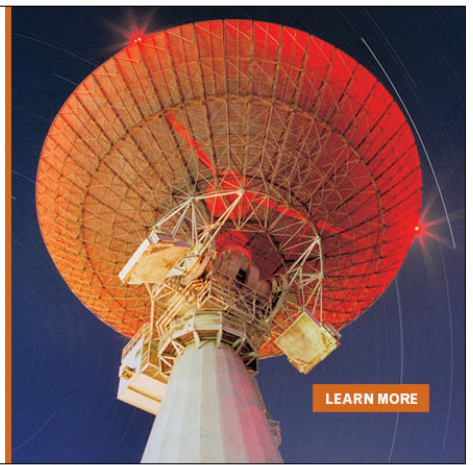




\title{
Porosity-induced relaxation of strains in GaN layers studied by means of micro-indentation and optical spectroscopy
}

\author{
Adel Najar, ${ }^{1}$ Michel Gerland, ${ }^{2}$ and Mustapha Jouiad ${ }^{1, a)}$ \\ ${ }^{1}$ King Abdullah University of Science and Technology, AMPM Center, 4700 Kaust, Thuwal 23955-6900, \\ Kingdom of Saudi Arabia \\ ${ }^{2}$ Institut PPrime, UPR 3346 CNRS, BP 40109, 86961 Futuroscope Chasseneuil, France
}

(Received 23 January 2012; accepted 31 March 2012; published online 4 May 2012)

\begin{abstract}
We report the fabrication of porous GaN nanostructures using UV-assisted electroless etching of bulk $\mathrm{GaN}$ layer grown on c-plane sapphire substrate in a solution consisting of $\mathrm{HF}: \mathrm{CH}_{3} \mathrm{OH}: \mathrm{H}_{2} \mathrm{O}_{2}$. The morphology of the porous GaN nanostructures was characterized for different etching intervals using high resolution scanning electron microscopy. The geometry and size of resultant pores do not appear to be affected by the etching time; however, the pore density was augmented for longer etching time. Micro-indentation tests were carried out to quantify the indentation modulus for different porous GaN nanostructures. Our results reveal a relationship between the elastic properties and the porosity kinetics, i.e., a decrease of the elastic modulus was observed with increasing porosity. The photoluminescence (PL) and Raman measurements carried out at room temperature for the etched samples having a high degree of porosity revealed a strong enhancement in intensity. Also, the peak of the PL wavelength was shifted towards a lower energy. The high intensity of PL was correlated to an increase of scattered photons within the porous media and to the reduction of the dislocation density. (C) 2012 American Institute of Physics. [http://dx.doi.org/10.1063/1.4710994]
\end{abstract}

\section{INTRODUCTION}

The fabrication of porous semiconductors has attracted a great deal of research interest in the field of sensing and epitaxy. Among the porous semiconductors being investigated, porous silicon receives enormous attention and has been investigated intensively. ${ }^{1-5}$ However, porous silicon has unstable chemical and physical properties, such as its susceptibility to oxidation at high surface/volume ratio ${ }^{6}$ as well as charge injection and trapping. ${ }^{7}$ These limitations will likely hinder the advancement of porous silicon in practical applications. An attractive alternative is to enhance the development of other porous III-V semiconductor compounds, such as $\mathrm{GaP}$, InP, and GaAs as well as the wide bandgap and corrosion resistant materials like $\mathrm{GaN}$ and $\mathrm{SiC}{ }^{8-13}$

Wide bandgap III-nitride semiconductors are generally grown on sapphire or $\mathrm{SiC}$ substrates. The GaN, sapphire, and $6 \mathrm{H}-\mathrm{SiC}$ semiconductors have in-plane lattice constants of $3.189 \AA$, $4.758 \AA$, and $3.08 \AA$, respectively, and have a thermal expansion coefficients of $5.59 \times 10^{-6} / \mathrm{K}, 7.5 \times 10^{-6} / \mathrm{K}$, and $4.2 \times 10^{-6} / \mathrm{K}$, respectively. ${ }^{14}$ The mismatches between the aforementioned constants and coefficients lead to high dislocation density at the interface of the overgrown layer, resulting in a high local stress field. Note that residual strain remains in the $\mathrm{GaN}$ layer, despite the partial relaxation of strain after the GaN epitaxial growth on the sapphire beyond a critical thickness of hundreds of $\mathrm{nm} .{ }^{15}$ Consequently, many investigations focused on achieving further reduction in residual strains and dislocation density. ${ }^{16-21}$ In particular, the development of porous GaN structure offers a significant enhancement with regards to the thermal, mechanical, and

\footnotetext{
a) Author to whom correspondence should be addressed. Electronic mail: mustapha.jouiad@kaust.edu.sa.
}

chemical stability as well as the potential to blue-shift of the band gap further into the ultraviolet region. ${ }^{22}$

The fabrication of porous GaN structure was first developed by Bardwell et $a .^{23}$ by means of a metal-assisted electroless chemical etching technique. In a typical synthesis, an ultrathin Pt catalyst layer was deposited on the semiconductor where the exposed area was etched in a HF: $\mathrm{CH}_{3} \mathrm{OH}: \mathrm{H}_{2} \mathrm{O}_{2}$ solution. The catalytic reduction of $\mathrm{H}_{2} \mathrm{O}_{2}$ at the $\mathrm{Pt}$ islands in conjunction with UV illumination injects holes into the semiconductor valence band and henceforth promotes the etching via the generation of oxidized atoms on the surface. The metal-assisted electroless etching method has proved to be an effective technique for the fabrication of the porous Si (Refs. 24 and 25) and the porous GaN (Ref. 22) nanostructures.

Herein, we report on the use of a UV electroless etching technique to fabricate porous GaN. The objective was twofold, i.e., to quantify the effect of porosity on the strains relaxation for the etched samples and to identify the impact of this relaxation on its optical properties using photoluminescence (PL) and Raman measurements.

\section{EXPERIMENTS}

The doped n-type GaN film used in this study was grown on a sapphire substrate, along the c-axis (0001), with a resistivity below $0.05 \Omega \mathrm{cm}$. The thickness and carrier concentration of the $\mathrm{GaN}$ film were estimated to be $30 \mu \mathrm{m}$ and $3.4 \times 10^{17} \mathrm{~cm}^{-3}$, respectively. The GaN samples were cleaved and cleaned by sonication in acetone and followed by 2propanol (i.e., $5 \mathrm{~min}$ in each solvent). It was then immersed in $\mathrm{HNO}_{3}$ at $65^{\circ} \mathrm{C}$ for $15 \mathrm{~min}$ and subsequently rinsed in deionized (DI) water and methanol, respectively. Two narrow stripes Pt (10 nm in thickness) separated by a few millimeters were deposited on the GaN samples using a sputtering system. 
The samples were etched in a HF: $\mathrm{CH}_{3} \mathrm{OH}: \mathrm{H}_{2} \mathrm{O}_{2}$ (2:1:2) solution under UV lamp with $500 \mathrm{~W}$ power. After chemical treatment, the samples were removed from the solution and rinsed with DI water.

The morphology of the resultant surfaces was analyzed using a high resolution SEM "Nova NanoSEM FEI" instrument equipped with an in-lens detection and beam deceleration, which allow resolution at approximately $2 \mathrm{~nm}$. The operating tension and beam current were set to $5 \mathrm{kV}$ and $58 \mathrm{pA}$, respectively. The PL and Raman spectroscopy measurements were performed at room temperature using Jobin Yvon LabRAM HR $800 \mathrm{UV}$ system. A He - Cd laser emitting at $325 \mathrm{~nm}$ and a diode-pumped solid-state (DPSS) laser emitting at $532 \mathrm{~nm}$ were used as the excitation sources for PL and Raman measurements, respectively. The incident laser power for both measurements was set to $20 \mathrm{~mW}$. The mechanical properties of the asgrown and porous $\mathrm{GaN}$ samples were characterized using an instrumented ultramicro-indenter "Leica H100C" equipped with a Vickers indenter (diamond pyramid with a face angle of $136^{\circ}$ ). A two-stage experiment was conducted whereby a maximum load of $100 \mathrm{mN}$ was applied onto the GaN layer for $20 \mathrm{~s}$ and during the second stage a creep sequence was applied for $15 \mathrm{~s}$ at the maximum load. Microhardness was calculated from the depth measurement of the indenter inside the material at the end of the creep time. The difference in the depth between the end and the beginning of creep gives an indication of the creep tendency of the material. The indentation modulus was obtained from the slope of the unloading curve, after the creep time. Two or three series of 49 indentations (square of $7 \times 7$ indentations) were performed on each sample in order to omit any scattering that may have occurred from the measurements.

\section{RESULTS AND DISCUSSIONS}

Figure 1 illustrates the SEM of the porous GaN samples prepared using two etching times (a) $45 \mathrm{~min}$ and (b) $90 \mathrm{~min}$. At higher magnification, both samples reveal the presence of uniform pores with an ellipsoidal morphology. However, it was observed that the pore density of the sample etched for $90 \mathrm{~min}$ was quite higher, as further confirmed by enhancing the threshold features of the image, e.g., Fig. 2. The diameter of the average cylinder-like pores are estimated to be $\sim 65 \mathrm{~nm}$, whereas the average coalesced pores are much larger, i.e., in the range of $\sim 100 \mathrm{~nm}$ to $\sim 380 \mathrm{~nm}$. It is noteworthy to mention that the presence of elongated pores is due to the merging of cylinderlike pores as the etchant thins the sidewall of the pores as they become closer. This is likely related to the high pore density obtained for longer etching time. This is especially evident for the sample etched for $90 \mathrm{~min}$. Moreover, the enhancement of the threshold features of the images (Fig. 2) allowed measuring the porosity that was estimated to be $17.5 \%$ and $32 \%$ for the samples etched for $45 \mathrm{~min}$ and $90 \mathrm{~min}$ duration, respectively.

The results of the micro-indentation tests are given in Table I. For all samples considered in this study, the microhardness and the indentation modulus drastically decrease when the etching duration is increased. For the sample etched for $45 \mathrm{~min}$, the micro-hardness and indentation modulus were found to be $6.23 \mathrm{GPa}$ and $172 \mathrm{GPa}$, respectively, and for the sample etched for $90 \mathrm{~min}$, they were found to be
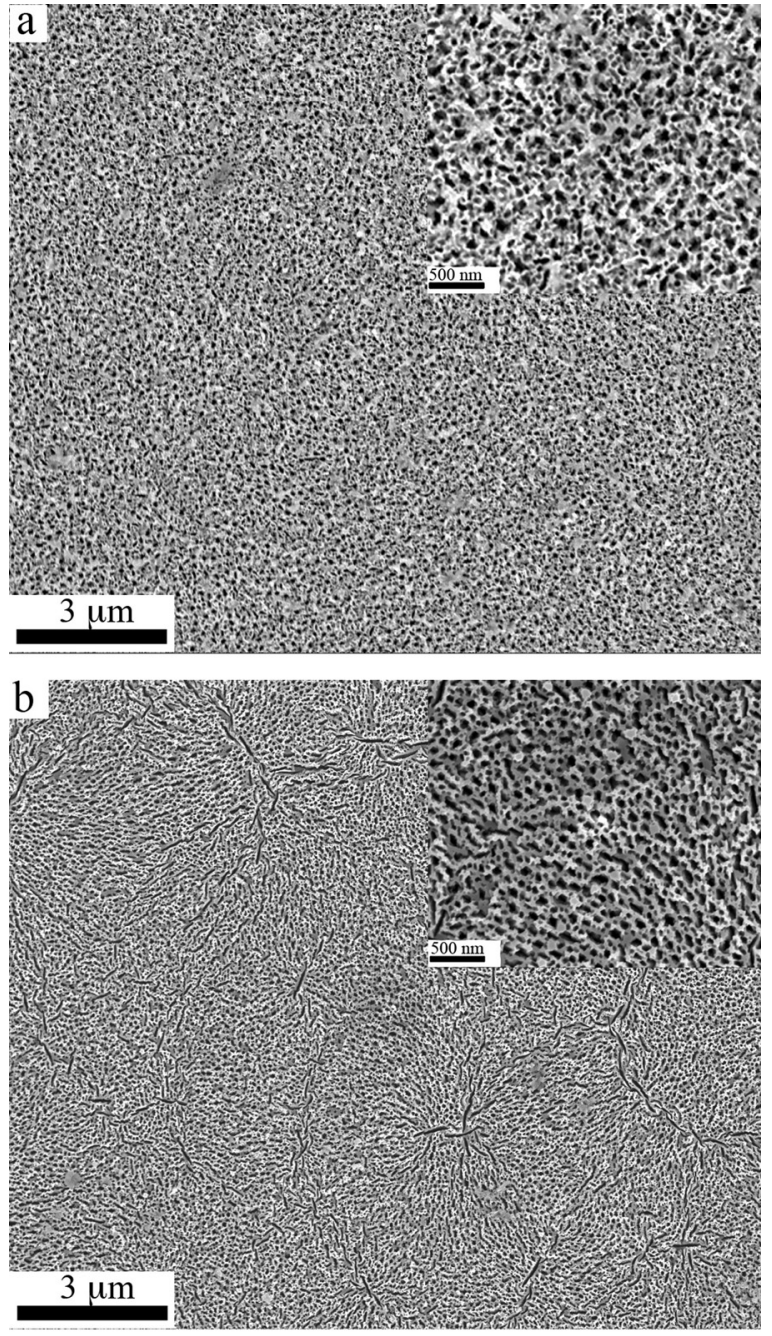

FIG. 1. SEM of the porous GaN nanostructures prepared using electroless chemical etching technique: (a) for $45 \mathrm{~min}$ and (b) for $90 \mathrm{~min}$. The insets are the zoom in window.

$1.23 \mathrm{GPa}$ and $91 \mathrm{GPa}$, respectively. The scattering was insignificant for the as-grown GaN layer but appears to be higher for the etched samples. The indentation modulus obtained for as-grown sample (i.e., $275 \mathrm{GPa}$ ) is in agreement with the values given by Kisielowski et al. ${ }^{16}$ The decrease of the micro-hardness and the indentation modulus corresponds to a stress relaxation linked to the etching process. The creep tests were conducted on these samples at a maximum load of $100 \mathrm{mN}$; the measured strains relaxation appeared to be low and comparable for all tested samples, e.g., $\sim 1 \%$ to $\sim 1.8 \%$ for the etched samples and as-grown sample, respectively. This means that the maximum load of $100 \mathrm{mN}$ did not introduce additional strain relaxation to the porous samples. This is another argument to support that the observed microhardness and indentation modulus decreasing is directly related to the formation of the pores during the etching process. In order to quantify the relationship between porosity and stress relaxation, the ratio $\mathrm{E} / \mathrm{E}_{0}$ (E and $\mathrm{E}_{0}$ are the Young modulus for the porous $\mathrm{GaN}$ samples and the as-grown sample, respectively) versus porosity $(\mathrm{P})$ is given in Fig. 3. The dependence of $\mathrm{E} / \mathrm{E}_{0}$ ratio on porosity obeys to the law of mixture given by the following equation: 

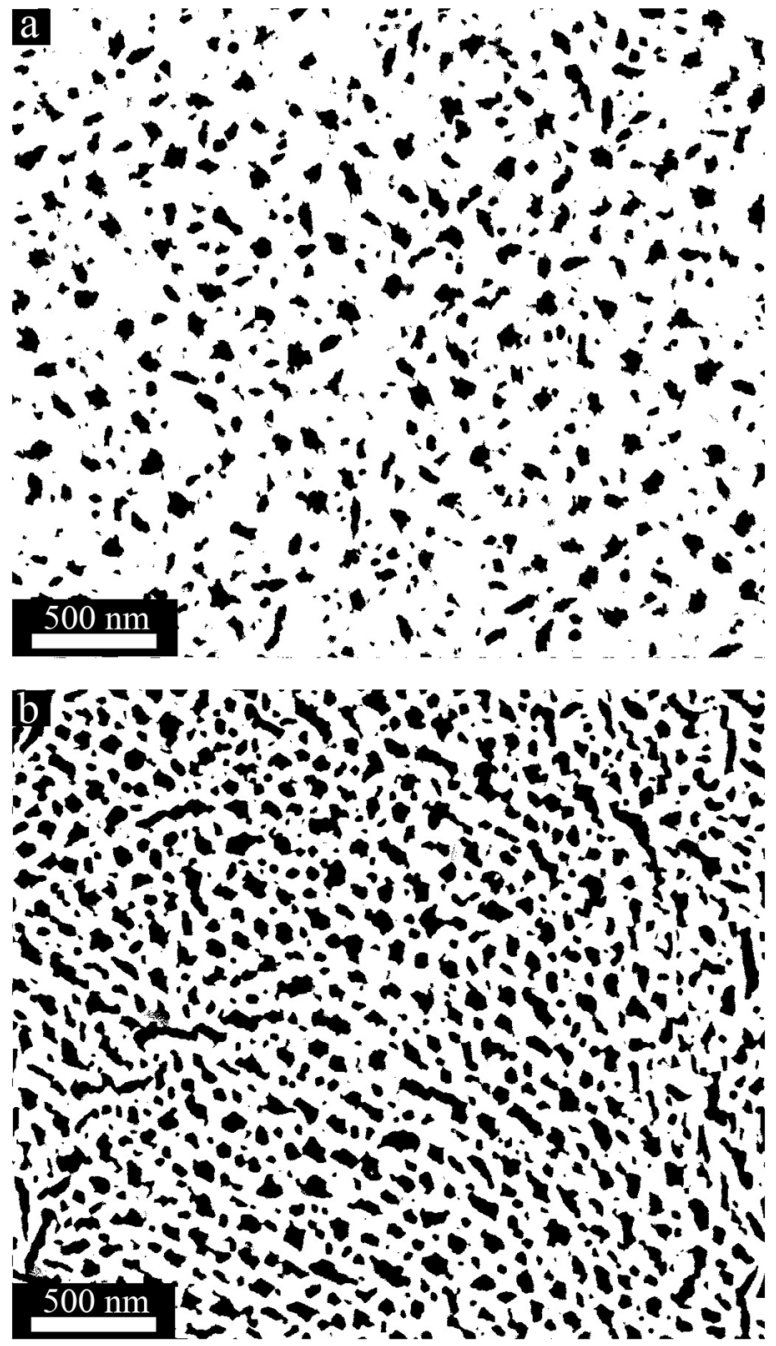

FIG. 2. Porosity determination using the image threshold enhancement: (a) porosity of $17.5 \%$ for the sample etched for $45 \mathrm{~min}$ and (b) $32 \%$ for the sample etched for $90 \mathrm{~min}$.

$$
\frac{E}{E_{0}}=1-\alpha \cdot P
$$

where $\alpha$ is a constant directly linked to the geometry of the pores as described earlier by Rossi. ${ }^{26}$ Based on his model applied to spherical pores, Rossi approximated $\alpha$ for a material having a Poisson ratio of 0.2 by the equation

$$
\alpha=\frac{5}{4}\left(\frac{a}{b}\right)+\frac{3}{4}
$$

where $\mathrm{a}$ and $\mathrm{b}$ are, respectively, the major and minor axes of the pore ellipsoidal like shape. This equation applies quite well to the GaN films, ${ }^{16}$ which exhibits a Poisson ration of

TABLE I. Mechanical properties as measured by the micro-indentation tests.

\begin{tabular}{lcccc}
\hline \hline & $\mathrm{HV}(\mathrm{GPa})$ & $\mathrm{E}(\mathrm{GPa})$ & $\varepsilon(\%)$ & $\zeta(\mathrm{mm})$ \\
\hline As-grown & $16.5 \pm 0.09$ & $275 \pm 1.5$ & $1.85 \pm 0.15$ & $0.541 \pm 0.002$ \\
45 min & $6.32 \pm 0.91$ & $172 \pm 16$ & $1.14 \pm 0.31$ & $0.989 \pm 0.071$ \\
$90 \mathrm{~min}$ & $1.23 \pm 0.34$ & $91 \pm 12$ & $0.74 \pm 0.10$ & $2.218 \pm 0.057$ \\
\hline \hline
\end{tabular}

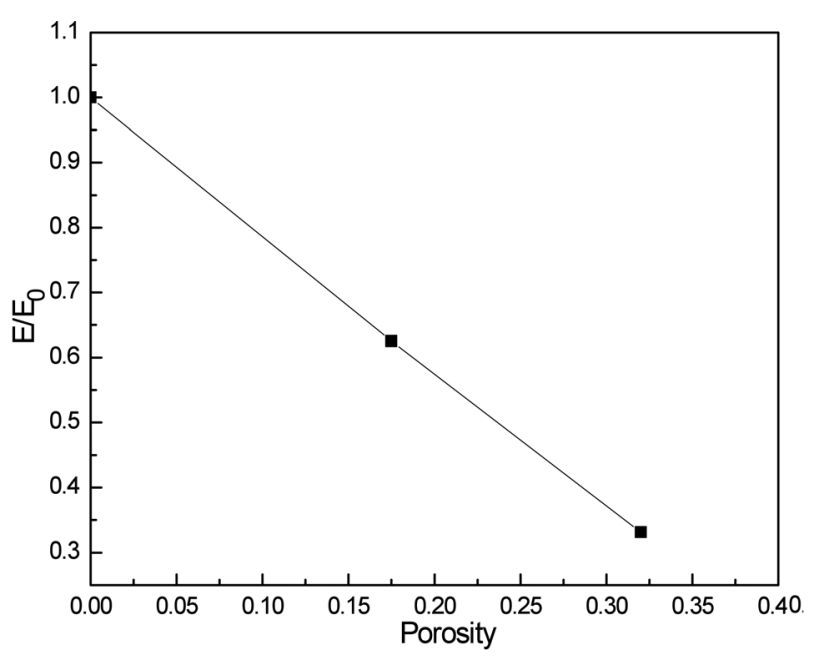

FIG. 3. $E / E_{0}$ ratio dependence on porosity $P$ where $E_{0}$ and $E$ are the indentation modulus of the as-grown and porous sample, respectively: $\frac{E}{E_{0}}=1-\alpha \cdot P$.

$\nu=0.23 \pm 0.06 ;$ hence, $\alpha=2.1$ and $\frac{a}{b}=1.08$ are deduced from Eqs. (1) and (2).

Interestingly, these results reveal that this etching technique is an efficient method to be used in the development of pores with respect to the mixture law that allows predicting the loss of elastic properties. Indeed, the electroless etching technique kinetics monitors the porosity and in fine allows measuring the $\mathrm{E} / \mathrm{E}_{0}$ ratio. The reduction in elastic properties in turn gives information of the strain relaxation experienced by the material according to Hook's Law

$$
\sigma=E \cdot \varepsilon
$$

where $\sigma$ is the axial stress, $\mathrm{E}$ is the Young modulus, and $\varepsilon$ is the elastic strain.

Based on the optical properties examination of the porous GaN material, the estimated values of in-plane and compressive strains relaxation will be given in Table III.

Indeed, a strong enhancement in PL intensity was observed in all etched samples as compared to that of the as-grown sample, e.g., 3 times (Fig. 4). The PL intensity increases when the

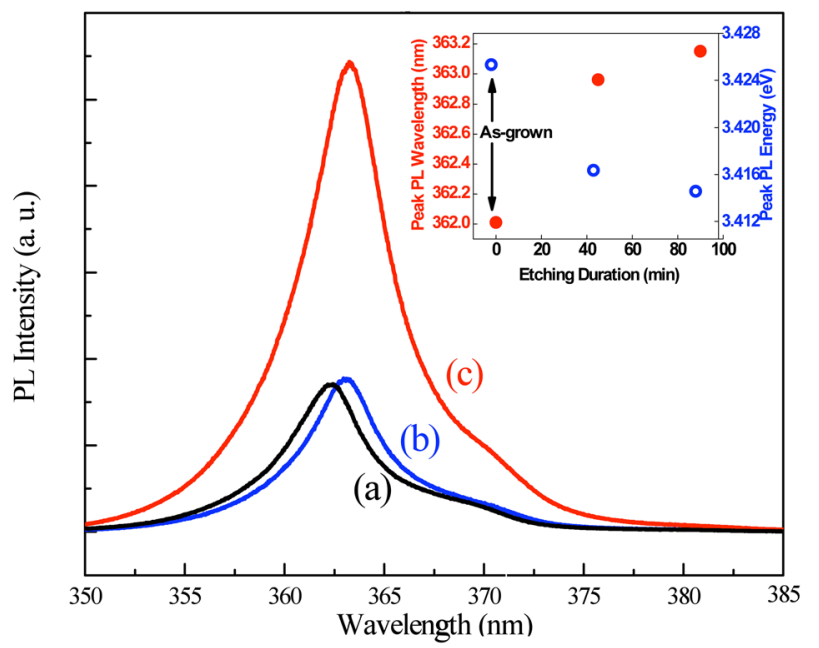

FIG. 4. Room temperature PL spectrum of the GaN samples: (a) as-grown, (b) etched for $45 \mathrm{~min}$, and (c) etched for $90 \mathrm{~min}$. The inset highlights the change in peak PL wavelength and the corresponding peak PL energy. 


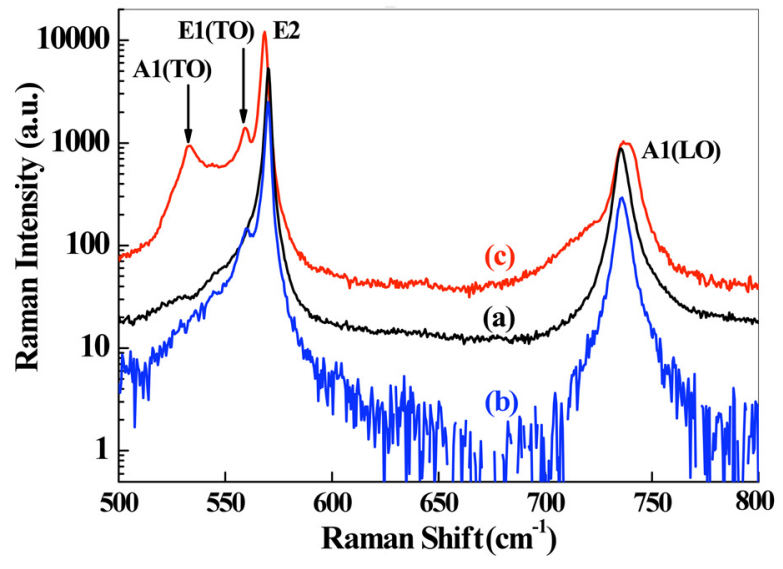

FIG. 5. The Raman spectrum of the GaN samples: (a) as-grown, (b) etched for $45 \mathrm{~min}$, and (c) etched for $90 \mathrm{~min}$.

porosity is increased which can be attributed to the reduction of dislocation density, an increase in photon extraction efficiency and the existence of scattering sidewalls in the GaN porous nanostructures as described elsewhere. ${ }^{27}$

In parallel, Raman spectra for both etched porous $\mathrm{GaN}$ samples and the as-grown sample are shown in Fig. 5. The phonon peak positions of samples are summarized in Table II. The Raman intensity of the two porous samples also appears to be enhanced after etching process; the reason being the same as for the enhancement of the porosity-induced PL intensity. The Raman spectra reveal that the $\mathrm{E}_{1}(\mathrm{TO})$ peaks are visible for the etched samples, whereas the $A_{1}(T O)$ was only observed for the sample etched during $90 \mathrm{~min}$. The presence of the TO peaks, which is actually forbidden according to Raman selection rules when the samples are measured in the back-scattered configuration, is a signature of the optical properties change as a result of the porosity. The $\mathrm{E}_{2}$ peak positions are located at $570.0 \mathrm{~cm}^{-1}, 568.5 \mathrm{~cm}^{-1}$, and $570.0 \mathrm{~cm}^{-1}$ for the samples that underwent etching times of $45 \mathrm{~min}, 90 \mathrm{~min}$, and for the as-grown sample, respectively. Note that the shift in the $E_{2}$ peak for the 45 min sample is to be neglected; this is likely due to the limitations imposed by the CCD-based Raman spectroscopy, i.e., $\Delta \omega=0.5 \mathrm{~cm}^{-1}$. However, a larger shift of $\Delta \omega=1.5 \mathrm{~cm}^{-1}$ towards the lower wave number was measured for the sample that underwent a $90 \mathrm{~min}$ etching duration. In addition, a new mode appeared for the sample etched for $90 \mathrm{~min}$ at $720 \mathrm{~cm}^{-1}$. This peak is attributed to Fröhlich mode due to the anisotropy etching. This latter has also been reported in columnar GaN prepared by illumination assisted anodic etching. ${ }^{28} \mathrm{We}$ anticipated the GaN epitaxy to experience a residual biaxial or in-plane tensile strain $\left(\varepsilon_{x x}=\varepsilon_{y y}\right)$ due to the fact that GaN has a smaller in-plane free-space lattice constant compared to that of the sapphire substrate. On the other hand, the lattice along the growth

TABLE II. Raman peak positions measured on GaN samples.

\begin{tabular}{lcccc}
\hline \hline & $\mathrm{E}_{2}\left(\mathrm{~cm}^{-1}\right)$ & $\mathrm{A}_{1}(\mathrm{TO})\left(\mathrm{cm}^{-1}\right)$ & $\mathrm{E}_{1}(\mathrm{TO})\left(\mathrm{cm}^{-1}\right)$ & $\mathrm{A}_{1}(\mathrm{LO})\left(\mathrm{cm}^{-1}\right)$ \\
\hline As-grown & 570.0 & $\ldots$ & $\ldots$ & 735.6 \\
$45 \mathrm{~min}$ & 570.0 & $\ldots$ & 560.0 & 736.1 \\
$90 \mathrm{~min}$ & 568.5 & 533.3 & 559.4 & 736.6 \\
\hline \hline
\end{tabular}

direction experiences uni-axial compressive strain $\left(\varepsilon_{z z}\right)$, as dictated by the Poisson effect. These physical quantities can be evaluated using Raman spectroscopy as per the following equations: ${ }^{16}$

$$
\begin{gathered}
\sigma_{x x}=\frac{\Delta \omega}{K} \\
\sigma_{z z}=2 \cdot \nu \cdot \frac{\Delta \omega}{K}
\end{gathered}
$$

where $\sigma_{x x}$ and $\sigma_{z z}$ are the in-plane and compressive stresses, respectively. $\Delta \omega$ is the Raman shift, $\mathrm{K}$ is the absolute calibration constant for the Raman shift $\Delta \omega$, and $\nu$ is the Poisson ratio.

$\mathrm{K}$ was reported to be equal to $\sim 4.2 \mathrm{~cm}^{-1} / \mathrm{GPa}$ (Refs. 16 and 29) and $\sim 2.56 \mathrm{~cm}^{-1} / \mathrm{GPa}^{19,30}$ This scattering of $\mathrm{K}$ values was highlighted and discussed by Harima. ${ }^{31}$

The combination of the Eqs. (3)-(5) permits linking the in-plane and compressive strains, respectively, to the Raman shift measured on porous GaN samples

$$
\begin{gathered}
\varepsilon_{x x}=\frac{\Delta \omega}{E \cdot K}, \\
\varepsilon_{z z}=\frac{2 \cdot \nu \cdot \Delta \omega}{E \cdot K},
\end{gathered}
$$

Table III gives the strains relaxation deduced from the Raman shift measured on porous GaN samples etched for $90 \mathrm{~min}$ for different given literature values of $\mathrm{K}$. This result, when compared to the creep tests performed for different samples at a maximum load of $100 \mathrm{mN}$, clearly shows that the pores generated by the electroless etching technique introduce significant relief of strains by increasing dislocation traps (side walls increase the free surface at the vicinity of the active dislocations). This results in low creep relaxation measured during the indentation tests. Furthermore, since the as-grown sample contains a high dislocation density due to the lattice mismatch between the GaN layer and sapphire substrate, it shows higher strain relaxation during the creep tests. This shows a high-energy dissipation due to the pre-existing internal stresses. Moreover, even if the measured strain relaxation is relatively low, it is still of great importance for the GaN sample because it belongs to a class of materials that exhibit a very high Young modulus. These are usually called brittle materials because they have a very low deformation at failure thereby avoiding high strain relaxation.

In summary, this study confirmed that a low cost controlled etching technique is an efficient method for decreasing strain relaxation in a highly constrained $\mathrm{GaN}$ film grown

TABLE III. In-plane and compression strains relaxation determined on the porous $\mathrm{GaN}$ etched for $90 \mathrm{~min}$ for different values of $\mathrm{K}$ given by the literature. $^{16,19,27,28}$

\begin{tabular}{lccccc}
\hline \hline & $\mathrm{K}\left(\mathrm{cm}^{-1} / \mathrm{GPa}\right)$ & $\sigma_{x x}(\mathrm{GPa})$ & $\sigma_{z z}(\mathrm{GPa})$ & $\varepsilon_{x x}(\%)$ & $\varepsilon_{z z}(\%)$ \\
\hline $90 \mathrm{~min}$ & 4.2 & 0.36 & 0.18 & 0.4 & 0.2 \\
2.56 & 0.55 & 0.27 & 0.6 & 0.3 & \\
\hline \hline
\end{tabular}


on a sapphire substrate. The strain relaxation decrease, measured by two different techniques namely micro-indentation and Raman spectroscopy, was found to significantly enhance the optical properties of the porous GaN.

\section{CONCLUSION}

A UV-assisted electroless etching technique was carried out on a GaN film grown on a sapphire substrate. A porosity time dependence was evidenced and the relationship between porosity and reduction in elastic properties was determined, which appeared to obey to the mixture law: $\frac{E}{E_{0}}=1-\alpha \cdot P$. A strong correlation between the porous $\mathrm{GaN}$ nanostructures and the relaxation of the in-plane and compressive strains was established. The strain relaxation was quantified using creep tests and Raman spectroscopy. Additionally, its impact on optical properties of GaN was examined. Indeed, the PL measurements reveal that the peak PL positions of the porous GaN samples were red-shifted. This was attributed to the relief of the uni-axial stress in the porous GaN samples. The PL intensities of the porous $\mathrm{GaN}$ samples increased with etching duration due to an increase in the PL extraction efficiency, and light scattering from the sidewalls of the GaN crystallites, as well as a reduction of the dislocation density.

${ }^{1}$ L. T. Canham, Appl. Phys. Lett. 57, 1046, (1990).

${ }^{2}$ A. Najar, J. Charrier, N. Lorrain, L. Haji, and M. Oueslati, Appl. Phys. Lett. 91, 121120 (2007).

${ }^{3}$ A. Najar, H. Ajlani, J. Charrier, N. Lorrain, S. Haesaert, M. Oueslati, and L. Haji, Physica B 396, 145 (2007).

${ }^{4}$ A. Matoussi, F. Ben Nasr, T. Boufaden, R. Salh, Z. Fakhfakh, S. Guermazi, B. Eljani, and H. J. Fitting, J. Lumin. 130, 399 (2010).

${ }^{5}$ A. Najar, N. Lorrain, H. Ajlani, J. Charrier, M. Oueslati, and L. Haji, Appl. Surf. Sci. 256(3), 581-586 (2009).

${ }^{6} \mathrm{~J}$. Mizsei, Thin Solid Films 515, 8310 (2007).

${ }^{7}$ J. Mizsei, J. A. Shrair, and I. Zólomy, Appl. Surf. Sci. 235, 376 (2004).
${ }^{8}$ L. Brus, J. Phys. Chem. 98, 3575 (1994).

${ }^{9}$ I. M. Tiginyanu, V. V. Ursaki, L. Sirbu, M. Enaki, and E. Monaico, Phys. Status Solidi C 6(7), 1587 (2009).

${ }^{10}$ D. D. Cheng, M. J. Zheng, L. J. Yao, S. H. He, L. Ma, W. Z. Shen, and X. Y. Kong, Nanotechnology 20, 425302 (2009).

${ }^{11}$ N. K. Ali, M. R. Hashim, A. Abdul Aziz, H. Abu Hassan, and J. Ismail, Electrochem. Solid-State Lett. 12(3), 9 (2009).

${ }^{12}$ H. Elhouichet, S. Daboussi, H. Ajlani, A. Najar, A. Moadhen, M. Oueslati, I. M. Tiginyanu, S. Langa, and H. Föll, J. Lumin. 113, 329 (2005).

${ }^{13}$ K. Al-Heuseen, M. R. Hashim, and N. K. Ali, Appl. Surf. Sci. 257, 6197 (2011).

${ }^{14}$ H. Morkoç, S. Strite, G. B. Gao, M. E. Lin, B. Sverdlov, and M. Burns, J. Appl. Phys. 76, 1363 (1994).

${ }^{15}$ C. Kim, I. K. Robinson, J. Myoung, K. Shim, M.-C. Yoo, and K. Kim, Appl. Phys. Lett. 69(16), 2358 (1996).

${ }^{16}$ C. Kisielowski, J. Krüger, S. Ruvimov, T. Suski, J. W. Ager III, E. Jones, Z. Liliental-Weber, M. Rubin, and E. R. Weber, Phys. Rev. B 54(24), 17745 (1996).

${ }^{17}$ I.-H. Lee, I.-H. Choi, C. R. Lee, and S. K. Noh, Appl. Phys. Lett. 71, 1359 (1997).

${ }^{18}$ L. T. Romano, C. G. Van de Walle, J. W. Ager, W. Götz, and R. S. Kern, J. Appl. Phys. 87(11), 7745 (2000).

${ }^{19}$ D. G. Zhao, S. J. Xu, M. H. Xie, D. S. Y. Tong, and H. Yang, Appl. Phys. Lett. 83(4), 677 (2003).

${ }^{20}$ F. K. Yam, Z. Hassan, and S. S. Ng, Thin Solid Films 515, 3469 (2007).

${ }^{21}$ I. M. Tiginyanu, V. V. Ursaki, V. V. Zalamai, S. Langa, S. Hubbard, D. Pavlidis, and H. Föll, Appl. Phys. Lett. 83, 1551 (2003).

${ }^{22}$ X. Li, Y. W. Kim, P. W. Bohn, and I. Adesida, Appl. Phys. Lett. 80, 980 (2002).

${ }^{23}$ J. A. Bardwell, I. G. Foulds, J. B. Webb, H. Tang, J. Fraser, S. Moisa, and S. J. Rolfe, J. Electron. Mater. 28, 24 (1999).

${ }^{24}$ X. Li and P. W. Bohn, Appl. Phys. Lett. 77, 2572 (2000).

${ }^{25}$ S. Chattopadhyay, X. Li, and P. W. Bohn, J. Appl. Phys. 91, 6134 (2002).

${ }^{26}$ R. C. Rossi, J. Am. Ceram. Soc. 51(8), 433 (1968).

${ }^{27}$ A. P. Vajpeyi, S. Tripathy, S. J. Chua, and E. A. Fitzgerald, Physica E 28, 141 (2005).

${ }^{28}$ I. M. Tiginyanu, A. Sarua, G. Irmer, J. Monecke, S. Hubbard, D. Pavlidis, and V. Valiaev, Phys. Rev. B 64, 233317 (2001).

${ }^{29}$ M. Jamil, J. R. Grandusky, V. Jindal, F. Shahedipour-Sandvik, S. Guha et al., Appl. Phys. Lett. 78(14), 82103-1 (2001).

${ }^{30}$ J.-M. Wagner and F. Bechstedt, Appl. Phys. Lett. 77, 346 (2000).

${ }^{31}$ H. Harima, J. Phys. Condens. Matter 14, 967 (2002). 